Review

\title{
trans-Resveratrol as A Neuroprotectant
}

\section{Ellen L. Robb and Jeffrey A. Stuart*}

Department of Biological Sciences, Brock University, St. Catharines, ON, L2S 3A1, Canada; E-Mail: ellen.robb@brocku.ca

* Author to whom correspondence should be addressed; E-Mail: jstuart@brocku.ca; Tel.: +1-905-688-5550, ext. 4814/4166.

Received: 31 December 2009; in revised form: 17 February 2010 / Accepted: 2 March 2010 / Published: 3 March 2010

\begin{abstract}
Epidemiological evidence indicates that nutritionally-derived polyphenols such as resveratrol (RES) have neuroprotective properties. Administration of RES to culture media protects a wide variety of neuronal cell types from stress-induced death. Dietary supplementation of RES can ameliorate neuronal damage and death resulting from both acute and chronic stresses in rodents. The specific molecular mechanisms by which RES acts at the cellular level remain incompletely understood. However, many experimental data indicate that RES reduces or prevents the occurrence of oxidative damage. Here we discuss possible mechanisms by which RES might exert protection against oxidative damage and cell death. Evidence suggesting that RES's chemical antioxidant potential is not sufficient explanation for its effects is discussed. Putative biological activities, including interactions with estrogen receptors and sirtuins are critically discussed. We provide a synthesis of how RES's phytoestrogenic properties might mediate the neuronal stress resistance underlying its observed neuroprotective properties.
\end{abstract}

Keywords: resveratrol; mitochondria; MnSOD; superoxide dismutase; reactive oxygen species; ROS; estrogen; phytoestrogen; stress resistance; neuroprotection

\section{Introduction}

The efficacy of nutritionally derived compounds as neuroprotective agents is increasingly supported by empirical evidence. Plant-derived molecules including polyphenols have demonstrated neuroprotective activities in cell culture and animal models. However, the molecular mechanisms that 
give rise to their protective effects are generally not well understood. Elevated levels of oxidative damage and an increased occurrence of cell death are common observations in chronic neurodegenerative diseases and acute ischemic injury. Polyphenols are small molecule antioxidants that are hypothesized to offer protection against the negative effects of oxidative stress in many tissues including brain, and this may underlie their ability to protect against cell death. Although dietary sources of antioxidants are extensive, a great deal of research interest has been directed towards the compounds found in red wine.

Resveratrol (RES), a compound found in high concentrations in red wine, and related polyphenols, have inherent antioxidant capacity due to their chemical structure. Direct antioxidant properties were once posited to be responsible for their broad range of biological effects; however, limited bioavailability and relatively weak scavenging abilities make this unlikely. An alternative to direct chemical interactions is the possibility that RES and related polyphenols work to enhance endogenous intracellular defense systems and in turn protect against cellular stress, dysfunction and death.

We begin this review by first summarizing the literature supporting the neuroprotective actions of RES, followed by a critical review of recent findings regarding putative mechanisms of RES's actions at the cellular level. We then extend this discussion to dietary delivery strategies that may increase RES's bioavailability and thereby maximize its neuroprotective effects.

\section{RES as a Neuroprotectant-Experimental Evidence}

RES's neuroprotective activity has been demonstrated in a wide range of different experimental models including neuronal cell cultures and live animals (Table 1). Experiments with neuronal cell lines are too numerous to summarize here, so only selected examples are described. Micromolar concentrations of RES have been shown to prevent apoptotic cell death in cultured cerebellar [1] and dopaminergic [2] neurons exposed to $\mathrm{MPP}^{+}$, a model of Parkinson-like neurodegeneration. Similarly, RES protects rat brain hippocampal slices against oxygen and glucose deprivation, a model of ischemic brain injury. In vivo, dietary administration of RES to mice [6] or rats [12] confers protection against acute brain injury caused by transient middle cerebral artery occlusion or cardiac arrest, respectively. Delivery of RES in the diet also protects mice [7] and rats [9] against 1-methyl-4-phenyl1,2,3,3-tetrahydropyridine (MPTP)- and 6-hydroxydopamine (6-OHDA)-induced neurodegeneration in experimental models of Parkinson's disease. Dietary RES supplementation reduces plaque formation in brains of a transgenic mouse model of Alzheimer's disease [11]. In the primate species Microcebus murinus chronic dietary administration of RES, for up to 18 months confers improved performance in a variety of behavioural tests [13]. Thus, regular dietary supplementation with RES can provide neural protection against a variety of potentially cytotoxic stresses and ameliorates neurodegeneration resulting from both acute and chronic insults. 
Table 1. Evidence for resveratrol as a neuroprotectant.

\begin{tabular}{|c|c|c|c|c|}
\hline Model & Treatment & Stressor & Effect & Reference \\
\hline Cerebellar granule neurons & $24 \mathrm{~h}$ of $1-100 \mu \mathrm{M}$ RES & MPP + & Antiapoptotic & {$[1]$} \\
\hline PC12 cells & $3 \mathrm{~h}$ of $100 \mu \mathrm{M}$ RES & $\mathrm{MPP}^{+}$ & Antiapoptotic & [2] \\
\hline SH-SY5Y cells & $1 \mathrm{~h}$ of $5 \mu \mathrm{M}$ RES & Dopamine & Antiapoptotic & [3] \\
\hline SH-SY5Y cells & $\begin{array}{l}24-72 \mathrm{~h} \text { of } 1-50 \mathrm{uM} \\
\text { RES }\end{array}$ & $\begin{array}{l}\mathrm{H}_{2} \mathrm{O}_{2} \text {, paraquat or } \\
\text { menadione }\end{array}$ & $\begin{array}{l}\text { Reduced incidence of } \\
\text { cell death }\end{array}$ & $\begin{array}{l}\text { Robb and Stuart } \\
\text { unpublished }\end{array}$ \\
\hline $\begin{array}{l}\text { PC12 cells co-cultured } \\
\text { with N9 microglia }\end{array}$ & $27 \mathrm{~h}$ of $100 \mu \mathrm{M}$ RES & LPS treatment & Antiapoptotic & [4] \\
\hline Rat hippocampal slices & Acute $100 \mu \mathrm{M}$ RES & $\begin{array}{l}\text { Oxygen-glucose } \\
\text { deprivation }\end{array}$ & Neuroprotective & [5] \\
\hline Mice & $50 \mathrm{mg} / \mathrm{kg} /$ day gavage & $\begin{array}{l}\text { Middle cerebral } \\
\text { artery occlusion }\end{array}$ & Neuroprotective & [6] \\
\hline Mice & $50-100 \mathrm{mg} / \mathrm{kg} /$ day & MPTP & $\begin{array}{l}\text { Prevented loss of DA } \\
\text { neurons }\end{array}$ & [7] \\
\hline Mice & $\begin{array}{l}\text { Acute RES at } 30 \mathrm{mg} / \mathrm{kg} \\
\text { i.v. }\end{array}$ & МРTP & $\begin{array}{l}\text { Reduced oxidative } \\
\text { damage; protected DA } \\
\text { neurons }\end{array}$ & [8] \\
\hline Mice & $\begin{array}{l}10-40 \mathrm{mg} / \mathrm{kg} / \mathrm{d} \text { for } 10 \\
\text { wks }\end{array}$ & 6-OHDA & $\begin{array}{l}\text { Reduced neuronal } \\
\text { damage }\end{array}$ & [9] \\
\hline $\begin{array}{l}\text { Inducible p } 25 \text { Alzheimer's } \\
\text { mouse model }\end{array}$ & $\begin{array}{l}2.5 \mu \mathrm{g} \text { RES injected } \\
\text { into lateral brain } \\
\text { ventricles }\end{array}$ & N.A. & Neuroprotective & {$[10]$} \\
\hline $\begin{array}{l}\text { Tg } 19959 \text { mouse } \\
\text { Alzheimer's model }\end{array}$ & $\begin{array}{l}300 \mathrm{mg} / \mathrm{kg} / \mathrm{d} \text { RES in } \\
\text { diet }\end{array}$ & N.A. & $\begin{array}{l}\text { Reduced plaque } \\
\text { pathology }\end{array}$ & [11] \\
\hline Rats & $\begin{array}{l}\text { 10-100 } \mu \mathrm{M} \text { RES by i.p. } \\
\text { injection }\end{array}$ & $\begin{array}{l}\text { Asphyxial cardiac } \\
\text { arrest }\end{array}$ & Neuroprotective & {$[12]$} \\
\hline
\end{tabular}

\subsection{RES ameliorates oxidative stress}

Many different conditions of cellular stress are united by a common observation of oxidative damage. In both acute brain injuries [14] and chronic neurodegenerative diseases [15], increased levels of cellular oxidative damage are typically evident. Oxidative stress is broadly defined as a perturbation of cellular homeostasis such that the rate of reactive oxygen species (ROS) production exceeds that of their neutralization. If homeostasis is not re-established, oxidative stress may progress toward the initiation of apoptotic cell death and tissue degeneration. There is abundant evidence that RES plays a role in attenuating this process via its ability to ameliorate oxidative stress.

In neurons, ROS are produced primarily from the mitochondrial electron transport chain as electrons pass from reduced complexes directly to molecular oxygen. The resulting superoxide anion participates in a variety of reactions that produce hydrogen peroxide, hydroxyl radical and peroxynitrite, which are subsequently involved in the oxidation of DNA, proteins and membranes. An aberrant overproduction of mitochondrial ROS is thought to contribute to both acute and chronic 
neuronal stress and death. For example Parkinson's disease, which is characterized by the specific loss of dopaminergic neurons, can be induced by injection of 1-methyl-4-phenyl-1,2,3,6-tetrahydropyridine (MPTP) [7-8]. This toxin is converted to MPP+ in satellite cells, and then taken up by dopaminergic neurons and electrophoretically accumulated within the mitochondrial matrix where it inhibits respiratory complex I [16] and increases superoxide production. Isolated mitochondria from rats treated with rotenone, a similar model of Parkinsonism, display increased levels of superoxide production, as well as an increased propensity to undergo membrane permeability transition pore opening [17]. In these Parkinson's disease models, treatment with mitochondria-targeted antioxidants, such as Szeto-Schiller peptide and MitoQ, can prevent acute neurological injury and neurodegeneration [reviewed in 18]. Szeto-Schiller peptide SS-31 is a short peptide containing aromatic and basic amino acids that accumulates in mitochondria and may reduce ROS concentrations [19]. SS-31 protects neuronal cell lines against exogenous oxidants [20]. It has recently been shown to protect against MPTP neurotoxicity in mice in a dose dependent manner [21]. Thus, rodent models of acute neuronal injury and chronic neurodegenerative disease indicate an important role for mitochondria-derived ROS, and provide evidence for the benefits of mitochondria-targeted antioxidants.

Abundant evidence from neuronal cell culture experiments and in vivo models indicates that RESmediated neuroprotection occurs concomitantly with measureable reductions in the oxidative damage load. For example, RES reduces oxidative DNA damage in C6 Glioma cells exposed to hydrogen peroxide [22]. RES reduces stress-induced ROS production in cerebellar neurons [1]. In vivo, RES has been shown to decrease various biomarkers of cellular oxidative damage, including DNA oxidation and lipid peroxidation [23-28]. Taken together, these results support the interpretation that RES confers neuroprotection due to its activity as an antioxidant. However, it appears that the ability to induce the expression of endogenous antioxidant enzymes, rather than its chemical antioxidant activity per se, underlies the antioxidant capacity of RES.

\subsection{RES as a chemical antioxidant}

The neuroprotective actions of RES and related phenolics at the cellular and organism level have been attributed to their chemical antioxidant capacities. In vitro, RES may efficiently neutralize ROS via the donation of a hydrogen atom and indeed, RES does protect cultured cells against death induced by a variety of exogenous oxidative stressors [29-31]. The extrapolation of in vitro results to in vivo systems is cautioned by a number of important experimental limitations. In vitro studies of antioxidants often employ supraphysiological concentrations, and may be complicated by the potential of some compounds to act as pro-oxidants in vitro, generating ROS as they decompose or react with surrounding molecules (see [32] for a review). These pro-oxidants cause mild oxidative stress which induces cellular defense systems and in turn increases the ability to withstand subsequent stressors (i.e., hormesis). This is particularly important in the context of ischemia-reperfusion injury as exposure to a low grade, non-lethal stressor invokes the expression of enzymes capable of protecting against more severe stress. Currently, however, there is no evidence to support the hypothesis that RES generates significant quantities of ROS in cell culture media. Ungvari et al. found that human coronary arterial endothelial cells cultured in the presence of micromolar concentrations of RES produced lower levels of superoxide and hydrogen peroxide than control treated cells [33]. While the reduction in ROS 
production observed likely arises due to an increase in ROS detoxification, the data do not support a prooxidant role for RES.

In vitro, the location of an antioxidant compound is also an important consideration, as its effects will be different if it is sequestered in the culture media or accumulates within cells. MitoQ, a hydrophobic antioxidant synthesized with a mitochondrial targeting sequence [34], partitions in mitochondrial membranes and has been shown to protect against oxidative damage following ischemia-reperfusion injury in rats [35]. Similarly, RES is hydrophobic and may accumulate in membranes at concentrations sufficient to act as an antioxidant following chronic exposure. There is evidence for an association between RES and mitochondria, including direct interactions with electron transport chain complexes [36]. Interestingly, RES's protective effect against a range of exogenous stressors, including oxidants, in vitro persists when RES is withdrawn from the culture media prior to the addition of exogenous oxidants [37], suggesting that RES is not acting to buffer ROS in the culture media. It is unknown whether RES accumulates within cells to act as an antioxidant or if its biological activities are responsible for its ability to enhance cellular stress resistance. Further research into the intracellular localization and accumulation of RES is required to understand its mechanism of action within cells.

In contrast to many chemical antioxidants, RES has been reported to interact with a wide range of cellular systems with the potential to protect against cell death, and it is therefore unclear whether direct chemical antioxidant or biological activities are responsible for RES's ability to protect against oxidative stress in vitro [38]. In contrast, it is quite clear that in vivo RES's chemical antioxidant properties are unlikely to be important. Concentrations of RES necessary to achieve protective effects in vitro are supraphysiological, and extrapolation of RES's in vivo effects from these experiments is not possible. It is interesting to note that RES is a fairly weak antioxidant, and radical scavenging would likely be observed only at concentrations above 0.1M [39-40]. Plasma concentrations of RES in rodents following a pharmaceutical dose are typically in the low micromolar range, far below the concentrations required for chemical antioxidant effects [41]. In humans, an oral dose of $25 \mathrm{mg}$ only yields plasma concentrations of free RES in the low nanomolar range [42]. Additionally, RES and related phenolics are quickly metabolized to glucuronidated forms with reduced antioxidant capacities [43]. Given the low bioavailability of RES and the rapid appearance of its metabolites, it seems unlikely that RES's chemical antioxidant properties are important to its beneficial effects in vivo.

In spite of the low probability that RES can act as a chemical antioxidant in vivo, it does appear to ameliorate conditions associated with oxidative stress. Below we explore the hypothesis that RES protects against oxidative stress via an upregulation of antioxidant enzymes.

\section{RES and MnSOD}

Mitochondria possess endogenous defense systems to protect against oxidative stress. These systems include antioxidant enzymes that detoxify radicals and repair enzymes that maintain macromolecule integrity. Within this review, we will primarily focus on the mitochondrial antioxidant enzyme MnSOD, a nuclear encoded protein that is targeted to the mitochondria. Within the matrix MnSOD converts the superoxide anion to hydrogen peroxide which is further detoxified by the enzymes glutathione peroxidase (in mitochondria) or catalase (in cytosol following diffusion of hydrogen peroxide out of mitochondria). 
Transgenic overexpression of the mitochondrial superoxide dismutase MnSOD, is protective against oxidative stress in a wide variety of experimental contexts [44-47]. In vitro, MnSOD is capable of protecting neuronal cells from various oxidative stressors. Pheochromocytoma PC6 cells overexpressing MnSOD maintain mitochondrial membrane potential, intracellular ATP levels, and are resistant to apoptosis induced by a range of chemical stressors, including the Parkinson's mimetic MPTP [44]. Mattson et al. hypothesized that MnSOD induction protects hippocampal neurons from oxidative stress induced apoptosis in vitro by reducing membrane peroxidation [48].

The importance of MnSOD to neuron health is clearly supported by in vivo evidence from animal models. In mice, deletion of the MnSOD gene causes severe symptoms from birth including neurological defects, limiting lifespan to several weeks [49-50]. $\mathrm{MnSOD}^{+/}$mice show increased incidence of apoptotic cell death induced by oxidative stress in tissues including brain [51-52]. In contrast, overexpression of MnSOD in mice provides protection from stress induced cell death, including neurons. Transgenic mice that overexpress human MnSOD are protected from oxidative damage and neuron loss induced by ischemia and the neurotoxin MPTP [44]. In brain, elevation of MnSOD has been shown to attenuate neuron cell death in the event of oxidative stressors such as MPTP and 6-hydroxydopamine [53-54]. In transgenic mice that overexpress MnSOD, cortical neuronal apoptosis is reduced following chronic intermittent hypoxia. This is accompanied by a reduction in spatial learning deficits in the stressed mice [55]. A similar observation was recently reported in a transgenic murine model of Alzheimer's disease in which MnSOD was overexpressed [56]. It is clear from both in vivo and in vitro studies that MnSOD has an important role in neuroprotection. Below we explore the hypothesis that MnSOD is an important target of RES, and that many of the effects observed with the overexpression of MnSOD are similarly observed with RES.

\subsection{MnSOD is a target of resveratrol}

MnSOD was initially identified as an important target of RES following the observation that chronic treatment of normal human lung fibroblasts with micromolar concentrations of RES elicits a significant increase in the protein level and activity of MnSOD [57]. A similar increase in MnSOD has been reported in other cell lines treated with RES including coronary artery endothelial cells [33], aortic smooth muscle cells [58], and SH-SY5Y neuroblastoma cells [37]. In vivo, RES given in a high fat diet (200 mgRES/kg/day) increases MnSOD in brain tissue of mice [59]. The observation of increased MnSOD in vivo is a potential explanation of RES's neuroprotective effects as many similarities exist with MnSOD overexpression. For example, mice administered RES in their diet were found to be more resistant to MPTP induced dopaminergic neuron death, a finding that is consistent with increased MnSOD capacity in brain [7].

The implication of MnSOD as a specific target of RES both in vivo and in vitro has not yet been fully realized, but it may represent a critical mechanism behind RES's beneficial effects on human health. However, RES has been reported to interact with numerous signalling pathways that may be responsible for its broad range of cellular effects including an increase in MnSOD. Understanding the mechanism that leads to increased MnSOD and cellular stress resistance will be a substantial contribution to RES research. 


\subsection{RES as a phytoestrogen - induction of MnSOD}

A potential explanation for RES's cellular effects may be its action as a phytoestrogen, plant derived compounds that mimic the activity of $17-\beta$-estradiol (E2). RES, like the soy product genistein and other polyphenols is structurally similar to E2, with free hydroxyl groups and phenolic ring structures that are important in estrogen receptor binding [60]. RES interacts directly with estrogen receptors alpha and beta with $\mathrm{Ki}$ values of 4.33-7.9 micromolar and 7.12-23.73 micromolar respectively, though it appears to exert particularly strong transcriptional effects via ER $\beta$ [61; reviewed in 62]. Interestingly, both mitochondria and MnSOD are major downstream targets of E2 signaling ([63]; for A review see [64]). Borras et al. showed in MCF7 cells that E2 signaling enhances transcription of MnSOD and glutathione peroxidase (GPx), although the authors did not state whether a mitochondrial GPx isoform (1 or 4) was probed [63]. However, the authors did not correct their results for mitochondrial abundance, an important factor to consider when measuring the level and activity of mitochondrial proteins. Borras et al. also reported that mitochondria from females contained higher levels of MnSOD than males [65]. In addition to its reported ability to stimulate mitochondrial antioxidant enzymes, E2 is associated with mitochondrial biogenesis and the transcriptional regulation of components of the electron transport chain (see [66] for A review). Further research into estrogen mediated change in antioxidant capacity with respect to mitochondrial abundance is required.

Neither MnSOD nor GPx gene promoters contain estrogen response elements, suggesting the E2 induction of their transcription by phytoestrogens is indirect. Borras et al. [65] provided evidence for the involvement of the signal transduction pathway mediated by MAP kinase, ERK1/2 and NFKB. UO126, an inhibitor of MAP kinase phosphorylation, eliminated the effects on ROS detoxification observed in MCF-7 cells treated with E2. NFאB is a target of MAP kinases, and is capable of upregulating both MnSOD and GPx. Inhibition of NFאB prevented an increase in MnSOD and GPx in MCF-7 cells treated with E2, supporting its role in the E2 signaling cascade responsible for increases MnSOD [63].

Interestingly, E2 demonstrates neuroprotective effects similar to those observed with RES. Preincubation of dopaminergic neurons with E2 affords protection against superoxide anions produced by xanthine oxidase, and micromolar concentrations hydrogen peroxide [67]. In vivo, E2 has the capacity to prevent the loss of aconitase activity, a superoxide sensitive mitochondrial enzyme, in brain tissue of both male and female rats [68], an observation that is consistent with an increase in MnSOD activity. MnSOD overexpression alone is sufficient to confer neuroprotection in mice [56]. We propose that RES acts both in vitro and in vivo by direct agonistic activity with ER $\beta$, and probably to a lesser extent ER $\alpha$, to stimulate $\mathrm{NF \kappa B}$ mediated MnSOD transcription (Figure 1). Robb et al. demonstrated a progressive stimulation of MnSOD protein levels and activities in human lung fibroblasts (MRC5) incubated with $50 \mu \mathrm{M}$ RES [57]. This result has subsequently been repeated in C2C12 murine myoblasts and SH-SY5Y cells [37] and also shown in mouse brain tissue following dietary RES supplementation [59]. In culture, the RES-induced upregulation of MnSOD is associated with increased stress resistance in all three cell lines indicated above [37]. This is consistent with the interpretation that the RES-induced MnSOD upregulation plays a key role in preventing apoptotic death of neurons. 
Figure 1. A proposed pathway for the RES-induced stimulation of MnSOD transcription via estrogen receptor-mediated regulation of NFKB activity. Based on the E2-induced transcriptional upregulation of MnSOD and other mitochondrial proteins described by Borras et al. [63]. MAPK = mitogen activated protein kinase; ERK1/2 = extracellular signal regulated kinases $1 / 2 ; \mathrm{NF} \kappa \mathrm{B}=$ nuclear factor $\kappa \mathrm{B} ; \mathrm{MnSOD}=$ manganese superoxide dismutase.

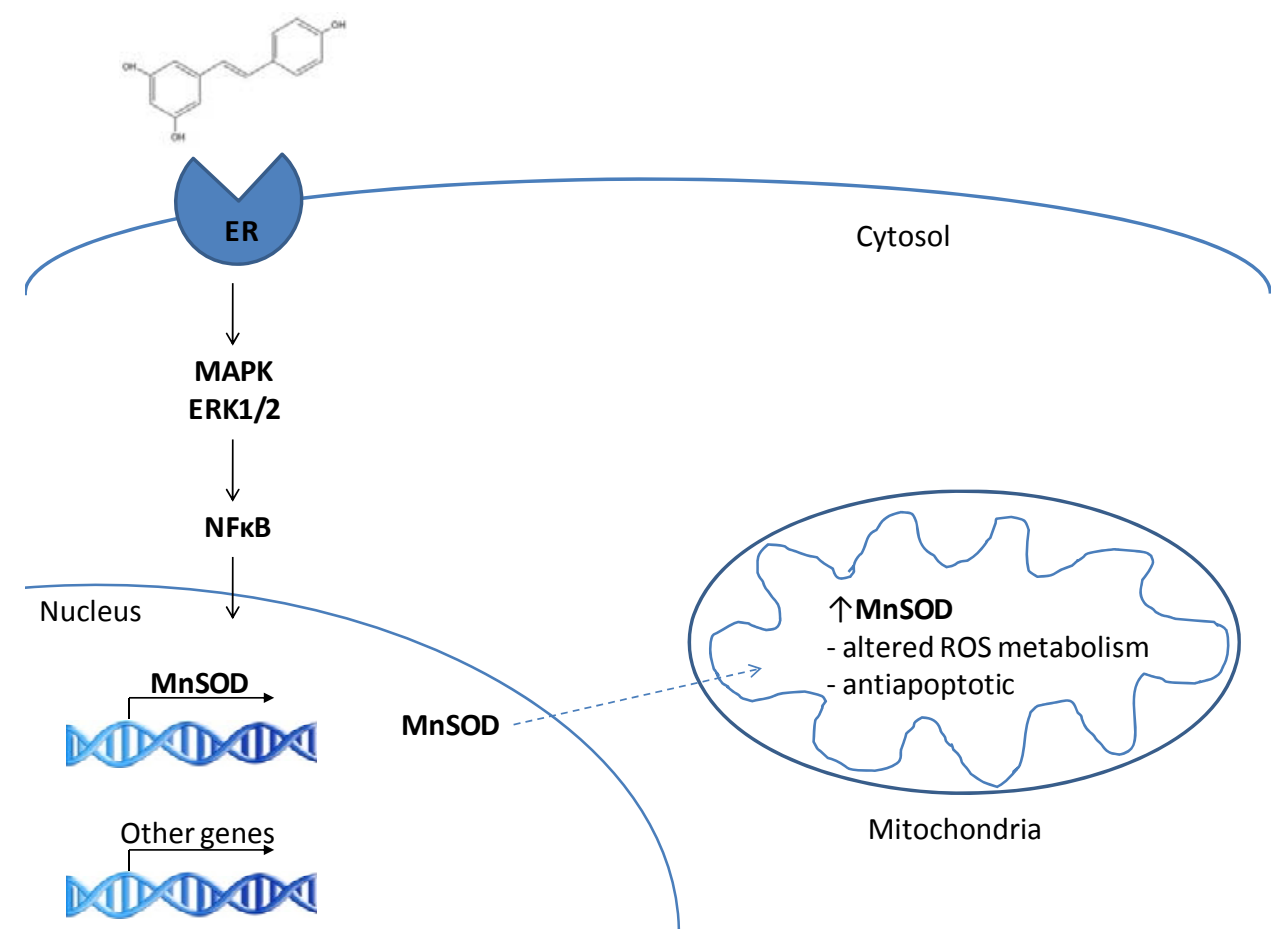

\section{RES and Sirtuins}

RES has gained considerable attention recently for its reported ability to activate sirtuins, a family of protein deacetylases implicated in lifespan regulation of organisms including yeast and worms [38]. Seven sirtuin isoforms have been identified in mammals, each with an apparently unique set of intracellular targets [69]. RES has been reported to activate SIR2 in yeast, and SIRT1 in mammals [70-73], and this has been offered as an explanation for many of RES's reported effects.

A neuroprotective activity of sirtuins has been widely suggested. However, while some experimental data support this, there are significant contradictions in the literature (see [74] for a review). Inhibition of SIRT1 activity with sirtinol negates the ability of a RES pre-treatment to protect SK-N-BE neuroblastoma cells from oxidative stress in culture, and hippocampal neurons from ischemic injury in a rat model of stroke secondary to cardiac arrest [12]. SIRT1 overexpression similarly has been shown to confer neuroprotection in a rodent model of Alzheimer's disease [10]. However, other authors have reported that sirtuins are dispensable for RES-mediated neuroprotection. Sirtinol inhibition of SIRT1 did not attenuate RES-mediated resistance to oxidative stressors in cerebellar granule neurons (CGN) in culture [1], and similarly had no effect on RES's ability to ameliorate plaque formation in a transgenic model of Alzheimer's disease [11]. The apparent contradiction between studies might be explained by an incomplete inhibition of SIRT1 at the sirtinol 
concentration used in some instances. However, Pfister et al. used two additional SIRT1 inhibitors, nicotinamide and splitomycin, and still failed to attenuate the RES-mediated protection of cultured CGN from oxidative stress [75]. In contrast, these authors demonstrated that, while SIRT1 overexpression was neuroprotective, this was independent of the enzyme's deacetylase activity as it was observed even when catalytically dead SIRT1 was expressed [75]. In addition to these negative results, two reports indicate that SIRT1 may actually sensitize neurons to cell death. Li et al. demonstrated that both pharmacological SIRT1 inhibition and SIRT1 gene knockout improved neuronal survival following exposure to some oxidative stressors [76]. Liu et al. similarly showed that SIRT1 inhibition reduced cell death in response to an excitotoxic insult, noting that intracellular NAD+ levels were maintained when SIRT1 was inhibited [77]. These observations were interpreted as a SIRT1-mediated depletion of NAD+ that could be lethal under certain conditions; prevention of this by SIRT1 inhibition could preserve [NAD+], thus ameliorating cell death [77].

The literature concerning the activation of SIRT1 by RES is similarly controversial. RES was first identified as an activator of SIRT1 in a fluorescent deacetylation assay using a synthetic peptide conjugated to a fluorescent moiety. RES reduced the $\mathrm{K}_{\mathrm{m}}$ value for the acetylated peptide by 35-fold, significantly altering SIRT1's substrate binding efficiency [71]. However, subsequent studies revealed that the RES dependent activation of SIRT1 was an artifact of the assay conditions used. Stimulation of SIRT1's deacetlyation activity with RES was measured in the presence or absence of a nonphysiological Fluor de Lys fluorophore. Three research groups found that RES increases the deacetylase activity of SIRT1 only in the presence of the Fluor de Lys fluorophore [78-80]. Using alternative assays that did not involve the Fluor de Lys fluorophore, Borra et al., Kaeberelein et al., and Beher et al. were unable to provide evidence that RES is capable of activating SIRT1 [78-80]. Taken together, we believe that the data presented to date are not strongly supportive of a central role for SIRT1 in mediating the neuroprotective activity of RES.

\section{Increasing RES Bioavailability}

While RES possesses a variety of beneficial biological activities, its pharmacological use is greatly limited by difficulties achieving therapeutic concentrations in vivo. Following dietary intake RES is rapidly metabolized and undergoes substantial chemical modification in the small intestine [81] or liver [82] and the majority of RES in human plasma following ingestion of the pure compound exists in its 3-O-glucuronide form [83]. On account of its rapid metabolism, supraphysiological doses of RES are required to elevate blood concentrations even slightly [23]. Studies in which rodents have been fed milligram quantities of the isolated compound have measured plasma levels of RES within the nanomolar to low micromolar range 30 minutes to 18 hours following intake [82,84-85]. The experimental concentrations mentioned above greatly surpass those achieved by red wine consumption, the most common dietary source of RES which are typically in the low micromolar range [83]. It may be the case that RES is capable of imparting neuroprotective effects at very low concentrations. Alternatively, tissue specific uptake of RES may be critical to its actions in vivo, and it's bioavailability in tissue may not be predicted by measurements of plasma RES levels alone. Few studies have examined the biological activities of RES derivatives, and it will be interesting to know if these compounds are capable of eliciting similar protective effects. 
Recently, Juan et al. reported an HPLC method capable of detecting RES in animal tissues at concentrations as low as $5.5 \mathrm{nM}$. This HPLC method was used to determine RES concentrations in tissues of rats administered intravenous RES at $15 \mathrm{mg} / \mathrm{kg}$ for 90 minutes. The accumulation of RES was lowest in brain, reaching only $0.17+/-0.04 \mathrm{nM} / \mathrm{g}$ tissue [86]. Interestingly, free RES comprised the greatest proportion of detected species in brain tissue, suggesting that the free form of RES is capable of crossing the blood brain barrier. In addition to evidence supporting the presence of RES in brain, El-Mohsen et al., found that the rate of RES clearance from brain tissue is substantially lower than in other organs. RES concentrations were measured via HPLC analysis of a methanol extraction from tissue two hours and 18 hours after RES administration. At 18 hours, the RES concentration decreased to only $43 \%$ of their initial measurement made two hours following RES administration. In comparison, RES concentration at $18 \mathrm{~h}$ fell to only $10 \%$ of the initial measurement in liver [82]. It is important to note that RES distribution in tissues and plasma is typically measured following a single dose of the compound. In contrast, many of the studies reporting RES's neuroprotective effects entail chronic, daily supplementation. Currently, little is current known regarding the potential for RES accumulation in tissues in studies involving long term, daily RES intake and elucidating the effect of chronic RES administration on tissue levels, particularly in brain, is an important next step in understanding the in vivo effects of this compound.

An equally important step in developing the therapeutic potential of RES is investigating how the delivery matrix can influence biological activities. Our previous work investigated the ability of three delivery methods to modulate tissue levels of antioxidant enzyme activities in mice: 1) RES incorporated into standard mouse chow; 2) RES incorporated into a high fat mouse chow and 3) RES in DMSO via a subcutaneous osmotic minipump. Delivery in a high fat diet elicited greater changes in cellular antioxidant activities in brain than the other two methods [59]. While the exact mechanisms that underlie the delivery-specific effects are unclear, it has been proposed that the inclusion of RES in a high fat diet protects it from degradation [87]. Alternative delivery systems that protect RES in the digestive tract without the negative consequences of a high fat diet may offer a new way to realize RES's positive effects on human health.

Carrier-mediated delivery of RES, including the use of nanoparticles is one potential means by which the challenges facing RES's bioavailability may be overcome. Two challenges facing the pharmaceutical development of RES are its instability and low solubility in water. Carriers that can modify these characteristics by encapsulating RES in a hydrophobic and stabilizing environment may offer a solution to RES's low bioavailability. The use of liposomal formulas to deliver other antioxidants molecules such as glutathione, vitamin $\mathrm{E}$ and $\mathrm{N}$-acetylcysteine has been previously reported with protective effects against disorders associated with oxidative stress [88]. Kristl et al., reported the development of a liposome carrier for RES that showed a protective effect against UV irradiation of human derived renal endothelial cells, using the reduction of MTT as an end point [89] While the results of the MTT assay are not necessarily representative of cell viability the RESliposomes appear to elicit a variety of changes that are not observed in the control groups [89]. The further development of methods to increase tissue concentrations of RES, particularly in brain, will be an important step in realizing the neuroprotective potential of this compound. 


\section{Conclusions}

There is now compelling evidence that dietary administration of RES can confer neuroprotection in rodents, raising the exciting possibility that it will prove to be similarly active in humans. The molecular mechanisms underlying RES's neuroprotective activities remain to be conclusively determined. Experiments with cultured cell lines suggest that the ability to selectively upregulate mitochondrial antioxidant gene expression, particularly MnSOD, may be important. This effect is achievable in vivo in mice, providing sufficiently high levels of RES are delivered in an appropriate dietary matrix. An important cellular target of RES may be ER $\beta$, due to RES's structural similarity to E2. An agonistic interaction with ER $\beta$ would explain how circulating RES concentrations that may be quite low (high nanomolar to low micromolar range) are capable of eliciting a significant antioxidant effect in brain tissue. Presumably, strategies capable of increasing RES bioavailability will enhance this desirable effect. Continued study using in vitro and in vivo experimental models will be required to achieve this goal.

\section{References}

1. Alvira, D.; Yeste-Velasco, M.; Folch, J.; Verdaguer, E.; Canudas, A.M.; Pallàs, M.; Camins, A. Comparative analysis of the effects of resveratrol in two apoptotic models: inhibition of complex I and potassium deprivation in cerebellar neurons. Neuroscience 2007, 147, 746-756.

2. Bournival, J.; Quessy, P.; Martinoli, M.G. Protective Effects of Resveratrol and Quercetin Against $\mathrm{MPP}(+)$-Induced Oxidative Stress Act by Modulating Markers of Apoptotic Death in Dopaminergic Neurons. Cell. Mol. Neurobiol. 2009, 29, 1169-1180.

3. Lee, M.K.; Kang, S.J.; Poncz, M.; Song, K.J.; Park, K.S. Resveratrol protects SH-SY5Y neuroblastoma cells from apoptosis induced by dopamine. Exp. Mol. Med. 2007, 39, 376-384.

4. Bureau, G.; Longpré, F.; Martinoli, M.G. Resveratrol and quercetin, two natural polyphenols, reduce apoptotic neuronal cell death induced by neuroinflammation. J. Neurosci. Res. 2008, 86, 403-410.

5. Zhang, H.; Schools, G.P.; Lei, T.; Wang, W.; Kimelberg, H.K.; Zhou, M.; Resveratrol attenuates early pyramidal neuron excitability impairment and death in acute rat hippocampal slices caused by oxygen-glucose deprivation. Exp. Neurol. 2008, 212, 44-52.

6. Dong, W.; Li, N.; Gao, D.; Zhen, H.; Zhang, X.; Li, F. Resveratrol attenuates ischemic brain damage in the delayed phase after stroke and induces messenger RNA and protein express for angiogenic factors. J. Vasc. Surg. 2008, 48, 709-714.

7. Blanchet, J.; Longpré, F.; Bureau, G.; Morissette, M.; DiPaolo, T.; Bronchti, G.; Martinoli, M.G. Resveratrol, a red wine polyphenol, protects dopaminergic neurons in MPTP-treated mice. Prog. Neuropsychopharmacol. Biol. Psychiatry 2008, 32, 1243-1250.

8. Lu, K.T.; Ko, M.C.; Chen, B.Y.; Huang, J.C.; Hsieh, C.W.; Lee, M.C.; Chiou, R.Y.; Wung, B.S.; Peng, C.H.; Yang, Y.L. Neuroprotective effects of resveratrol on MPTP-induced neuron loss mediated by free radical scavenging. J. Agric. Food Chem. 2008, 56, 6910-6913.

9. Jin, F.; Wu, Q.; Lu, Y.F.; Gong, Q.H.; Shi, J.S. Neuroprotective effect of resveratrol on 6-OHDAinduced Parkinson's disease in rats. Eur. J. Pharmacol. 2008, 600, 78-82. 
10. Kim, D.; Nguyen, M.D.; Dobbin, M.M.; Fischer, A.; Sananbenesi, F.; Rodgers, J.T.; Delalle, I.; Baur, J.A.; Sui, G.; Armour, S.M.; Puigserver, P.; Sinclair, D.A.; Tsai, L.H. SIRT1 deacetylase protects against neurodegeneration in models for Alzheimer's disease and amyotrophic lateral sclerosis. EMBO J. 2007, 26, 3169-3179.

11. Karuppagounder, S.S.; Pinto, J.T.; Xu, H.; Beal, M.F.; Gibson, G.E. Dietary supplementation with resveratrol reduces plaque pathology in a transgenic model of Alzheimer's disease. Neurochem. Int. 2009, 54, 111-118.

12. Della-Morte, D.; Dave, K.R.; DeFazio, R.A.; Bao, Y.C.; Raval, A.P.; Perez-Pinzon, M.A. Resveratrol pretreatment protects rat brain from cerebral ischemic damage via a sirtuin 1uncoupling protein 2 pathway. Neuroscience 2009, 159, 993-1002.

13. Dal-Pan, A.; Guignard, A.; George, E.; Aujard, F.; Picq, J.L. Resveratrol supplementation modified memory and physical performances in a primate. In Proceedings of the 4th International Conference on Polyphenols and Health, Yorkshire, UK, 7-10 December 2009; p. 387.

14. Blomgren, K.; Hagberg, H. Free radicals, mitochondria, and hypoxia-ischemia in the developing brain. Free Radic. Biol. Med. 2006, 40, 388-397.

15. Tsang, A.H.; Chung, K.K. Oxidative and nitrosative stress in Parkinson's disease. Biochim. Biophys. Acta 2009, 1792, 643-650.

16. Javitch, J.A.; D’Amato, R.H.; Strittmatter, S.M.; Snyder, S.H. Parkinsonism-inducing neurotoxin N-methyl-4-phenyl-1,2,3,6-terahydropyridine: uptake of the metabolite N-methyl-4phenylpyridine by dopamine neurons explains selective toxicity. Proc. Natl. Acad. Sci. USA 1985, 82, 2173-2177.

17. Panov, A.; Dikalov, S.; Shalbuyeva, N.; Taylor, G.; Sherer, T.; Greenamyre, J.T. Rotenone model of Parkinson disease: multiple brain mitochondria dysfunctions after short term systemic rotenone intoxication. J. Biol. Chem. 2005, 280, 42026-42035.

18. Chaturvedi, R.K.; Beal, M.F. Mitochondrial approaches for neuroprotection. Ann. N.Y. Acad. Sci. 2008, 1147, 395-412.

19. Szeto, H.H.; Cell-permeable, mitochondrial-targeted, peptide antioxidants. AAPS J. 2006, 8, E227-E283.

20. Zhao, K.; Luo, G.; Gianneli, S.; Szeto, H.H. Mitochondria-targeted peptide prevents mitochondrial depolarization and apoptosis induced by tert-butyl hydroperoxide in neuronal cell lines. Biochem. Pharmacol. 2005, 70, 1796-1806.

21. Yang, L.; Zhao, K.; Calingasan, N.Y.; Luo, G.; Szeto, H.H.; Beal, M.F. Mitochondria targeted peptides protect against 1-methyl-4-phenyl-1,2,3,6-tetrahydropyridine neurotoxicity. Antioxid. Redox Signal. 2009, 11, 2095-2104.

22. Quincozes-Santos, A.; Andreazza, A.C.; Nardin, P.; Funchal, C.; Gonçalves, C.A.; Gottfried, C. Resveratrol attenuates oxidative-induced DNA damage in C6 glioma cells. Neurotoxicity 2007, 28, 886-891.

23. Wenzel, E.; Soldo, T.; Erbersdobler, H.; Somoza, V. Bioactivity and metabolism of transresveratrol orally administered to Wistar rats. Mol. Nutr. Food Res. 2005, 49, 482-494.

24. Ates, O.; Cayli, S.; Altinoz, E.; Gurses, I.; Yucel, N.; Sener, M.; Kocak, A.; Yologlu, S. Neuroprotection by resveratrol against traumatic brain injury in rats. Mol. Cell Biochem. 2007, 294, 137-144. 
25. Guo, L.; Wang, L.H.; Sun, B.; Yang, J.Y.; Zhao, Y.Q.; Dong, Y.X.; Spranger, M.I.; Wu, C.F. Direct in vivo evidence of protective effects of grape seed procyanidin fractions and other antioxidants against ethanol-induced oxidative DNA damage in mouse brain cells. J. Agric. Food Chem. 2007, 5881-5891.

26. Yousuf, S.; Atif, F.; Ahmad, M.; Hoda, N.; Ishrat, T.; Khan, B.; Islam, F. Resveratrol exerts its neuroprotective effect by modulating mitochondrial dysfunctions and associated cell death during cerebral ischemia. Brain Res. 2009, 1250, 242-253.

27. Velioğlu-Oğunc, A.; Sehirli, O.; Toklu, H.Z.; Ozyurt, H.; Mayadağli, A.; Eksioğlu-Demiralp, E.; Erzik, C.; Cetinel, S.; Yeğen, B.C.; Sener, G. Resveratrol protects against irradiation-induced hepatic and ileal damage via its anti-oxidative activity. Free Radic. Res. 2009, 43, 1060-1071.

28. Wong, Y.T.; Gruber, J.; Jenner, A.M.; Ng, M.P.; Ruan, R.; Tay, F.E. Elevation of oxidativedamage biomarkers during aging in F2 hybrid mice: protection by chronic oral intake of resveratrol. Free Radic Biol Med. 2009, 46, 799-809.

29. Yu, W.; Fu, Y.C.; Zhou, X.H.; Chen, C.J.; Wang, X.; Lin, R.B.; Wang, W. Effects of resveratrol on H2O2-induced apoptosis and expression of SIRTs in H9c2 cells. J. Cell Biochem. 2009, 107, 741-747.

30. De Almeida, L.M.; Leite, M.C.; Thomazi, A.P.; Battu, C.; Nardin, P.; Tortorelli, L.S.; Zanotto, C.; Posser, T.; Wofchuk, S.T.; Leal, R.B.; Gonçalves, C.A.; Gottfried, C. Resveratrol protects against oxidative injury induced by $\mathrm{H} 2 \mathrm{O} 2$ in acute hippocampal slice preparations from Wistar rats. Arch. Biochem. Biophys. 2008, 480, 27-32.

31. Vieira de Almeida, L.M.; Pineiro, C.C.; Leite, M.C.; Brolese, G.; Leal, R.B.; Gottfried, C.; Conçalves, C.A. Protective effects of resveratrol on hydrogen peroxide induced toxicity in primary cortical astrocyte cultures. Neurochem. Res. 2008, 33, 8-15.

32. Halliwell, B. Are polyphenols antioxidants or pro-oxidants? What do we learn from cell culture and in vivo studies? Arch. Biochem. Biophys. 2008, 476, 1070112.

33. Ungvari, Z.; Labinskyy, N.; Mukhopadhyay, P.; Pinto, J.T.; Bagi, Z.; Ballabh, P.; Zhang, C.; Pacher, P.; Csiszar, A. Resveratrol attenuates mitochondrial oxidative stress in coronary arterial endothelial cells. Am. J. Physiol. Heart Circ. Physiol. 2009, 297, H1876-H1881.

34. Kelso, G.F.; Porteous, C.M.; Coulter, C.V.; Hughes, G.; Porteous, W.K.; Ledgerwood, E.C.; Smith, R.A.; Murphy, M.P. Selective targeting of a redox-active ubiquinone to mitochondria within cells: antioxidant an antiapoptotic properties. J. Biol. Chem. 2001, 276, 4588-4596.

35. Adlam, V.J.; Harrison, J.C.; Porteous, C.M.; James, A.M.; Smith, R.A.; Murphy, M.P.; Sammut, I.A. Targeting an antioxidant to mitochondria decreases cardiac ischemia-reperfusion injury. FASEB J. 2005, 19, 1088-1095.

36. Zini, R.; Morin, C.; Bertelli, A.; Bertelli, A.A.; Tillement, J.P. Effects of resveratrol on the rat brain respiratory chain. Drugs Exp. Clin. Res. 1999, 25, 87-97.

37. Robb, E.L.; Stuart, J.A.; Resveratrol targets the mitochondrial antioxidant enzyme manganese superoxide dismutase and increases cellular stress resistance. In Proceedings of the 4th International Conference on Polyphenols and Health, Yorkshire, UK, 7-10 December 2009; p.393.

38. Baur, J.A.; Sinclair, D.A. Therapeutic potential of resveratrol: the in vivo evidence. Nat. Rev. Drug Discov. 2006, 5, 493-506. 
39. Hu, Y.; Rahlfs, S.; Mersch-Sundermann, V.; Becker, K. Resveratrol modulates mRNA transcripts of gene related to redox metabolism and cell proliferation in on-small-cell lung carcinoma cells. Biol. Chem. 2007, 388, 207-219.

40. Leonard, S.S.; Xia, C.; Jiang, B.H.; Stinefelt, B.; Klandorf, H.; Harris, G.K.; Shi, X. Resveratrol scavenges reactive oxygen species and effects radical-induced cellular responses. Biochem. Biophys. Res. Commun. 2003, 309, 1017-1026.

41. Wenzel, E.; Somoza, V. metabolism and bioavailability of trans-resveratrol. Mol. Nutr. Food Res. 2005, 49, 472-481.

42. Walle, T.; Hsieh, F.; DeLegge, M.H.; Oatis, J.E., Jr.; Walle, U.K. High absorption but very low bioavailability of oral resveratrol in humans. Drug Metab. Dispos. 2004, 32, 1377-1382.

43. Williamson, G.; Barron, D.; Shimoi, K.; Terao, J. In vitro biological properties of flavonoid conjugates found in vivo. Free Radic. Res. 2005, 39, 457-469.

44. Keller, J.N.; Kindy, M.S.; Holtsberg, F.W.; St Clair, D.K.; Yen, H.C.; Germeyer, A.; Steiner, S.M.; Bruce-Keller, A.J.; Hutchins, J.B.; Mattson, M.P. Mitochondrial manganese superoxide dismutase prevents neural apoptosis and reduces ischemic brain injury: suppression of peroxynitrite production, lipid peroxidation, and mitochondrial dysfunction. J. Neurosci. 1998, $18,687-697$.

45. Lee, Y.J.; Cho, H.N.; Jeoung, D.I.; Soh, J.W.; Cho, C.K.; Bae, S.; Chung, H.Y.; Lee, S.J.; Lee, Y.S. HSP25 overexpression attenuates oxidative stress-induced apoptosis: roles of ERK1/2 signaling and manganese superoxide dismutase. Free Radic. Biol. Med. 2004, 36, 429-444.

46. Cruthirds, D.L.; Saba, H.; MacMillan-Crow, L.A. Overexpression of manganese superoxide dismutase protects against ATP depletion-mediated cell death of proximal tubule cells. Arch. Biochem. Biophys. 2005, 437, 96-105.

47. Silva, J.P.; Shabalina, I.G.; Dufour, E.; Petrovic, N.; Backlund, E.C.; Hultenby, K.; Wibom, R.; Nedergaard, J.; Cannon, B.; Larsson, N.G. SOD2 overexpression: enhanced mitochondrial tolerance by absence of effect on UCP activity. EMBO J. 2005, 24, 4061-4070.

48. Mattson, M.P.; Goodman, Y.; Luo, H.; Fu, W.; Furukawa, K. Activation of NF-kappaB protects hippocampal neurons against oxidative stress-induced apoptosis: evidence for induction of manganese superoxide dismutase and suppression of peroxynitrite production and protein tyrosine nitration. J. Neurosci. Res. 1997, 49, 681-697.

49. Li, Y.; Huang, T.T.; Carlson, E.J.; Melov, S.; Ursell, P.C.; Olson, J.L.; Noble, L.J.; Yoshimura, M.P.; Berger, C.; Chan, P.H.; Wallace, D.C.; Epstein, C.J. Dilated cardiomyopathy and neonatal lethality in mutant mice lacking manganese superoxide dismutase. Nat. Genet. 1995, 11, 376-381.

50. Lebovitz, R.M.; Zhang, H.; Vogel, H.; Cartwright, J. Jr.; Dionne, L.; Lu, N.; Huang, S.; Matzuk, M.M. Neurodegeneration, myocardial injury, and perinatal death in mitochondrial superoxide dismutase-deficient mice. Proc. Natl. Acad. Sci. USA 1996, 93, 9782-9787.

51. Van Remmen, H.; Ikeno, Y.; Hamilton, M.; Pahlavani, M.; Wolf, N.; Thorpe, S.R.; Alderson, N.L.; Baynes, J.W.; Epstein, C.J.; Huang, T.T.; Nelson, J.; Strong, R.; Richardson, A. Life-long reduction in MnSOD activity results in increased DNA damage and higher incidence of cancer but does not accelerate again. Physiol. Genomics 2003, 16, 29-37.

52. Loch, T.; Vakhrusheva, O.; Piotrowska, I.; Ziolkowski, W.; Ebelt, H.; Braun, T.; Bober, E. Different extent of cardiac malfunction and resistance to oxidative stress in heterozygous and 
homozygous manganese-dependent superoxide dismutase-mutant mice. Cardiovasc. Res. 2009, $82,448-457$.

53. Klivenyi, P.; St Clair, D.; Wermer, M.; Yen, H.C.; Oberley, T.; Yang, L.; Flint Beal, M. Manganese superoxide dismutase overexpression attenuates MPTP toxicity. Neurobiol. Dis. 1998, 5, 253-258.

54. Callio, J.; Oury, T.D.; Chu, C.T. Manganese superoxide dismutase protects against 6hydroxydopamine injury in mouse brains. J. Biol. Chem. 2005, 280, 18536-18542.

55. Shan, X.; Chi, L.; Ke, Y.; Luo, C.; Qian, S.; Gozal, D.; Liu, R. Manganese superoxide dismutase protects mouse cortical neurons from chronic intermittent hypoxia-mediated oxidative damage. Neurobiol. Dis. 2007, 28, 206-215.

56. Dumont, M.; Wille, E.; Stack, C.; Calingasan, N.Y.; Beal, M.F., Lin, M.T. Reduction of oxidative stress, amyloid deposition and memory deficit by manganese superoxide dismutase overexpression in a transgenic mouse model of Alzheimer's disease. FASEB J. 2009, 23, 24592466.

57. Robb, E.L.; Page, M.M.; Wiens, B.E.; Stuart, J.A. Molecular mechanisms of oxidative stress resistance induced by resveratrol: Specific and progressive induction of MnSOD. Biochem. Biophys. Res. Commun. 2008, 367, 406-412.

58. Li, Y.; Cao, Z.; Zhu, H. Upregulation of endogenous antioxidants and phase 2 enzymes by the red wine polyphenol, resveratrol in cultured aortic smooth muscle cells leads to cytoprotection against oxidative and electrophilic stress. Pharmacol. Res. 2006, 53, 6-15.

59. Robb, E.L.; Winkelmolen, L.; Visanji, N.; Brotchie, J.; Stuart, J.A. Dietary resveratrol administration increases MnSOD expression and activiyt in mouse brain. Biochem. Biophys. Res. Commun. 2008, 372, 254-259.

60. Le Bail, J.C.; Champavier, Y.; Chulia, A.J.; Habrioux, G. Effects of phytoestrogens on aromatase, 3 beta and 17beta-hydroxy-steroid dehydrogenase activities and human breast cancer cells. Life Sci. 2000, 66, 1281-1291.

61. Bowers, J.L.; Tyulmenkov, V.V.; Jernigan, S.C.; Klinge, C.M. Resveratrol acts as a mixed agonist/antagonist for estrogen receptors alpha and beta. Endocrinology, 2000, 141, 3657-3667.

62. Mense, S.M.; Hei, T.K.; Ganju, R.K.; Bhat, H.K. Phytoestrogens and breast cancer prevention: possible mechanisms of action. Environ. Health Perspect. 2008, 116, 426-433.

63. Borrás, C.; Gambini, J.; Gómez-Cabrera, M.C.; Sastre, J.; Pallardó, F.V.; Mann, G.E.; Vina, J. 17beta-oestradiol up-regulates longevity-related, antioxidant enzyme expression via the ERK1 and ERK2 MAPK/NFkappaB cascade. Aging Cell 2005, 4, 113-118.

64. Klinge, C.M. Estrogenic control of mitochondrial function and biogenesis. J. Cell Biochem. 2008, 105, 1342-1351.

65. Borrás, C.; Sastre, J.; Garcia-Sala, D.; Lloret, A.; Pallardó, F.V.; Vina, J. Mitochondria from females exhibit higher antioxidant gene expression and lower oxidative damage than males. Free Radic. Biol. Med. 2003, 34, 546-552.

66. Chen, J.Q.; Cammarata, P.R.; Baines, C.P.; Yager, J.D. Regulation of mitochondrial respiratory chain biogenesis by estrogens/estrogen receptors and physiological, pathological and pharmacological implications. Biochim. Biophys. Acta 2009, 1793, 1540-1570. 
67. Sawada, H.; Ibi, M.; Kihara, T.; Urushitani, M.; Akaike, A.; Shimohama, S. Estradiol protects mesencephalic dopaminergic neurons from oxidative stress-induced neuronal death. J. Neurosci. Res. 1998, 54, 717-719.

68. Razmara, A.; Duckles, S.P.; Krause, D.N.; Procaccio, V. Estrogen suppresses brain mitochondrial oxidative stress in female and male rats. Brain Res. 2007, 1176, 71-81.

69. Dali-Youcef, N.; Lagouge, M.; Froelich, S.; Koehl, C.; Schoonjans, K.; Auwerx, J. Sirtuins: the 'magnificent seven', function, metabolism and longevity. Ann. Med. 2007, 39, 335-345.

70. Wood, J.G.; Rogina, B.; Lavu, S.; Howitz, K.; Helfand, S.L.; Tatar, M.; Sinclair, D. Sirtuin activators mimic caloric restriction and delay ageing in metazoans. Nature, 2004, 430, 10031009.

71. Howitz, K.T.; Bitterman, K.K.; Cohen, H.Y.; Lamming, D.W.; Lavu, S.; Wood, J.G.; Zipkin, R.E.; Chung, P.; Kisielewski, A.; Zhang, L.L.; Scherer, B.; Sinclair, D.A. Small molecule activators of sirtuins extend Saccharomyces cerevisiae lifespan. Nature 2003, 425, 191-196.

72. Lagouge, M.; Argmann, C.; Gerhart-Hines, Z.; Meziane, H.; Lerin, C.; Daussin, F.; Messadeq, N.; Milne, J.; Lambert, P.; Elliott, P.; Geny, B.; Laakso, M.; Puigserver, P.; Auwerx, J. Resveratrol improves mitochondrial function and protects against metabolic disease by activation SIRT1 and PGC-1alpha. Cell 2006, 127, 1108-1122.

73. Baur, J.A.; Pearson, K.J.; Price, N.L.; Jamieson, H.A.; Lerin, C.; Kalra, A.; Prabhu, W.; Allard, J.S.; Lopez-Llunch, G.; Lewis, K.; Pistell, P.J.; Poosala, S.; Becker, K.G.; Boss, O.; Gwinn, D.; Wang, M.; Ramaswamy, S.; Fishbein, K.W.; Spencer, R.G.; Lakatta, E.G.; Le Couteur, D.; Shaw, R.J.; Navas, P.; Puigserver, P.; Ingram, D.K.; de Cabo, R.; Sinclair, D.A. Resveratrol improves health and survival of mice on a high-calorie diet. Nature 2006, 444, 337-342.

74. Tang, B.L. Sirtl's complex roles in neuroprotection, Cell. Mol. Neurobiol. 2009, 29, 1093-1103.

75. Pfister, J.A.; Ma, C.; Morrison, B.E.; D'Mello, S.R. Opposing effects of sirtuins on neuronal survival: SIRT1-mediated neuroprotection is independent of its deacetylase activity. PLoS One 2008, 3, e4090.

76. Li, Y.; Xu, W.; McBurney, M.W.; Longo, V.D. SirT1 inhibition reduces IGF-I/IRS2/Ras/ERK1/2 signaling and protects neurons. Cell Metab. 2008, 8, 38-48.

77. Liu, D.; Gharavi, R.; Pitta, M.; Gleichmann, M.; Mattson, M.P. Nicotinamide prevents NAD+ depletion and protects neurons against excitotoxicity and cerebral ischemia: NAD+ consumption by SIRT1 may endanger energetically compromised neurons. Neuromolecular. Med. 2009, 11, $28-42$.

78. Borra, M.T.; Smith, B.C.; Denu, J.M. Mechanism of human SIRT1 activation by resveratrol. J. Biol. Chem. 2005, 280, 17187-17195.

79. Kaeberlein, M.; McDonagh, T.; Heltweg, B.; Hixon, J.; Westman, E.A.; Caldwell, S.D.; Napper, A.; Curtis, R.; DiStefano, P.S.; Fields, S.; Bedalov, A.; Kennedy, B.K. Substrate-specific activation of sirtuins by resveratrol. J. Biol. Chem. 2005, 17038-17045.

80. Beher, D.; Wu, J.; Cumine, S.; Kim, K.W.; Lu, S.C.; Atangan, L; Wang, M. Resveratrol is not a direct activator of SIRT1 enzyme activity. Chem. Biol. Drug Des. 2009, 74, 619-624.

81. Kuhnle, G.; Spencer, J.P.; Chowrimootoo, G.; Schroeter, H.; Debnam, E.S.; Srai, S.K.; RiceEvans, C.; Hahn, U. Resveratrol is absorbed in the small intestine as resveratrol glucuronide. Biochem. Biophys. Res. Commun. 2000, 272, 212-217. 
82. El Mohsen, M.A.; Bayele, H.; Kuhnle, G.; Gibson, G.; Debnam, E.; Srai, S.K.; Rice-Evans, C.; Spencer J.P. Distribution of $[3 \mathrm{H}]$ trans-resveratrol in rat tissues following oral administration. $\mathrm{Br}$. J. Nutrit. 2006, 96, 62-70.

83. Goldberg, D.M.; Yan, J.; Soleas, G.J. Absorption of three wine-related polyphenols in three different matrices by health subjects. Clin. Biochem. 2003, 36, 79-87.

84. Marier, J.F.; Vachon, P.; Gritsas, A.; Zhang, J.; Moreau, J.P.; Ducharme, M.P. Metabolism and disposition of resveratrol in rats: extend of absorption, glucuronidation, nand enterohepatic recirculation evidenced by a linked-rat model. J. Pharmacol. Exp. Ther. 2002, 302, 369-373.

85. Sale, S.; Verschoyle, R.D.; Boocock, D.; Jones, D.J.; Wilsher, N.; Ruparelia, K.C.; Potter, G.A.; Farmer, P.B.; Steward, W.P.; Gescher, A.J. Pharmacokinetics in mice and growth-inhibitory properties of the putative cancer chemopreventative agent resveratrol and the synthetic analogue trans 3,4,5,4'-tetramethoxystilbene. Br. J. Cancer 2004, 90, 736-744.

86. Juan, M.E.; Maijó, M.; Planas, J.M. Quantification of trans-resveratrol and its metabolites in rat plasma and tissues by HPLC. J. Pharm. Biomed. Anal. 2010, 51, 391-398.

87. Vaz-da-Silva, M.; Loureiro, A.L.; Falcao, A.; Nunes, T.; Rocha, J.F.; Fernandes-Lopes, C.; Soares, E.; Wright, L.; Almeida, L.; Soares-da-Silva, P. Effect of food on the pharmacokinetic profile of trans-resveratrol. Int. J. Clin. Pharmacol. Ther. 2008, 46, 564-570.

88. Stone, W.L.; Smith, M. Therapeutic use of antioxidant liposomes. Mol. Biotechnol. 2004, 27, 217-230.

89. Kristl, J.; Teskac, K.; Caddeo, C.; Abramović, A.; Sentjurc, M. Improvements of cellular stress response on resveratrol in liposomes. Eur. J. Pharm. Biopharm. 2009, 72, 253-259.

(C) 2010 by the authors; licensee Molecular Diversity Preservation International, Basel, Switzerland. This article is an open-access article distributed under the terms and conditions of the Creative Commons Attribution license (http://creativecommons.org/licenses/by/3.0/). 